\author{
レーザー分光法による微量成分計測 \\ 野田 松平, 出口祥啓, 土橋 晋作, 吉川 孝三*, 岩㠃誠司** \\ 三菱重工業(株) 長崎研究所 (T851-0392 長崎市深堀町5-717-1) \\ *三菱重工業(株) 高砂研究所 ( $\mathrm{T}$ 676-8686 兵庫県高砂市荒井町新浜2-1-1) \\ **(財) 発電設備技術検查協会 東京エンジニアリングセンター（テ279-0011 千葉県浦安市美浜1-9-2)
}

\title{
Trace Element Detection Using Laser Diagnostics
}

\author{
Matsuhei NODA, Yoshihiro DEGUCHI, Shinsaku DOBASHI, \\ Kozo YOSHIKAWA,* and Seiji IWASAKI** \\ Nagasaki Research and Development Center, Mitsubishi Heavy Industries, Ltd. \\ 5-717-1 Fukahori-machi, Nagasaki 851-0392 \\ *Takasago Research and Development Center, Mitsubishi Heavy Industries, Ltd. \\ 2-1-1 Niihama, Arai-machi, Takasago, Hyogo 676-8686 \\ **Tokyo Engineering Center, Japan Power Engineering and Inspection Corporation \\ 1-9-2 Mihama, Urayasu, Chiba 279-0011
}

(Received September 6, 2000)

\begin{abstract}
This study demonstrates trace element measurement using laser diagnostics. A LIBS technique has been applied to detect alkali metals under high-pressure and high-temperature conditions, and an automated LIBS unit has been developed and applied in a month-long monitoring experiment. The results were compared to those obtained using the conventional sampling method, and good agreement was found. LIBS can detect Na and $\mathrm{K}$ at ppb levels, even under the high-pressure conditions of PFBC and IGCC thermal power plants. LIBS is capable of a 1-minute detection time, as opposed to the 20-hour sampling time required by the conventional method, and offers various advantages as a tool for actual plant monitoring.
\end{abstract}

Key Words: Laser spectroscopy, Trace element, LIBS, Alkali metals, Real time monitoring

\section{1. 緒 言}

近年, 環境負荷低減が求められる中, 燃焼ガス中に存在 するppt〜ppbレベルの微量成分が問題視されてきている. また, 微量成分は機器の寿命に大きな影響を与え,ガス夕ー ビンへ流入するアルカリ成分などはその濃度を把握及び 管理する必要がある。従来, これらの物質は長時間のサン プリング後, 化学分析を行っていたため, 計測結果を得る までに時間を要していた。これら成分のオンライン計測 が強く望まれており,このニーズに応える定量可能な手法 の開発が急務となっている.

本研究では, 上記アルカリ成分のin-situ計測手法として, LIBS法 (Laser Induced Breakdown Spectroscopy, レーザー誘 起ブレークダウン法)を取り上げ, LIBS法を火力プラント へ適用することを目的として, ガス中アルカリ成分の計測 を実施した。温度・圧力等の計測条件は, 実機プラント条 件と同等レベルとし, 精度, 計測時間, 安定性等の把握を行 い, 実プラントへの適用性を評価した。

\section{LIBSの概要}

LIBS法は, 物質の成分組成を非接触で計測可能なレー ザー計測法であり,排ガス中の各種金属原子1), フライアッ シュ成分 2,3$)$, セメント材料中の成分計測 3 , 空気中アルカリ 成分計測4)等に応用されている。

\section{1 原 理}

LIBSの原理をFig.1に示す. LIBSでは, 計測場にレーザー 光を集光し, 計測対象をプラズマ化する．このとき,プラ ズマ中の物質は原子化され, 各原子固有の波長の光を放射 する.このプラズマ光を分光分析することで, その中に含 まれる成分濃度を検出することができる，LIBSにおける プラズマ発光強度は, (1)式で表される.

$$
I_{i}=k_{i} n_{i} \sum_{j}\left[g_{i}^{(j)} \exp \left\{-\frac{E_{i}^{(j)}}{k T}\right\}\right]
$$

ここで, $I_{i}$ は化学種 $i$ 発光強度, $k_{i}$ は化学種 $i$ に依存した係 数, $n_{i}$ は化学種 $i$ の成分濃度, $g_{i}$ は化学種 $i$ 多重度と遷移確率 の積, $E_{i}$ は上位準位エネルギ, $k$ はボルツマン定数, $T$ はプラ 


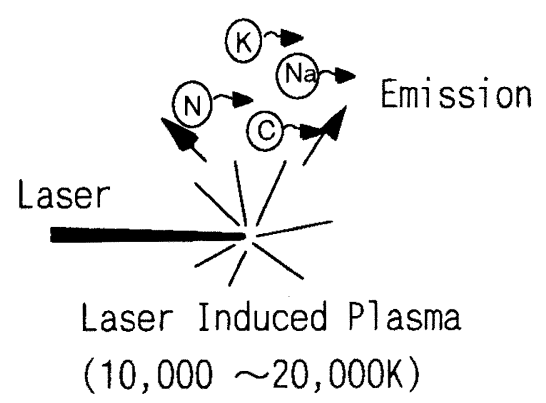

Fig.1 LIBS plasma process.

ズマ温度を示す，jは, 化学種 $i$ 発光に寄与する上位準位 を示す。

\section{3. 試験装置}

本研究では, 長期テスト燃焼炉と高圧・高温試験炉を用 いて研究を行った．各装置の概略を以下に示す。

\section{1 長期計測テスト燃焼炉}

燃焼ガス中のアルカリ成分の長期計測試験に用いたテ スト燃焼炉をFig.2に示す。装置は, 燃料タンク,バーナ部, 燃焼室, 計測部から成る。バーナは, 燃焼室前に取り付け られており, 燃焼ガスは試験室にて希勫され, 所定温度の 燃焼ガスが得られる。アルカリ成分として $\mathrm{NaCl}, \mathrm{Na}_{2} \mathrm{SO}_{4}$ を バーナ部に添加した。

主な燃焼条件を以下に示す。

・燃焼ガス温度：873K

. 燃料：灯油

・燃焼ガス量 : $283 \mathrm{~m}^{3} \mathrm{~N} / \mathrm{h}$

本試験では, LIBS並びにサンプリング法(JIS-K8808；排 ガス中ダスト濃度の測定方法, JIS-K0095；排ガス採取方 法)を用いてNa濃度を計測した。

\section{2 高温・高圧試験炉}

高温・高圧試験装置をFig.3に示す。試験には高圧・高 温流通管式試験装置を使用した。装置は, ガス供給装置, 高 温・高圧チャンバー, 計測試験部から成る。本装置の仕様 を以下に示す。

·圧力 : $0.1 \sim 3.0 \mathrm{MPag}$

- 温度 : $300 \sim 1,500 \mathrm{~K}$

Burner Control Unit

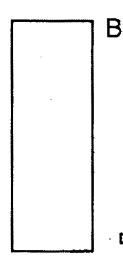

Fuel Tank

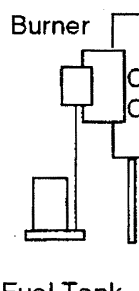

Sampling Unit

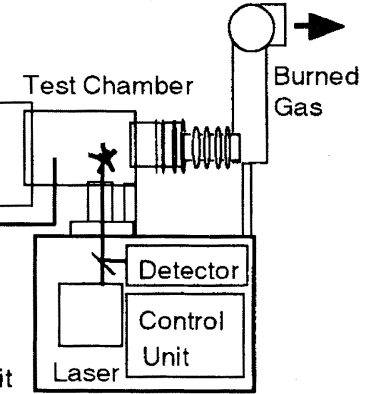

LIBS Analyzer
Fig.2 Long term test combustor.

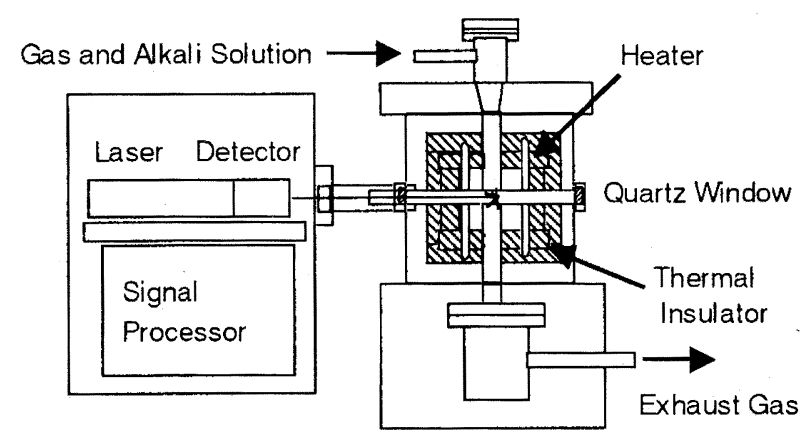

Fig.3 High temperature and high pressure furnace.

ガス組成 $\left(\mathrm{N}_{2}, \mathrm{CO}_{2}, \mathrm{O}_{2}, \mathrm{H}_{2}\right)$ が所定の濃度に調整された混 合ガスをボンべより供給し, $\mathrm{NaCl}$ 及び $\mathrm{KCl}$ 溶液を添加する ことによりアルカリ成分を供給した，溶液濃度, 添加量を 変化させることにより,計測試験部のアルカリ濃度を変化 させ,LIBS計測に及ぼす圧力及びアルカリ金属濃度の影響 を調べた。

\subsection{LIBS装置}

LIBS装置をFig.4に示す，本装置は三菱重工(株)製であ り, 計測, デー夕転送, 装置の正常作動管理等が全て自動化 されている。本装置では $800 \mathrm{~mJ} / \mathrm{p}, 10 \mathrm{~Hz}$ のパルスYAGレー ザーを使用した。レーザー光を計測空を介して排ガス中

Spectrograph

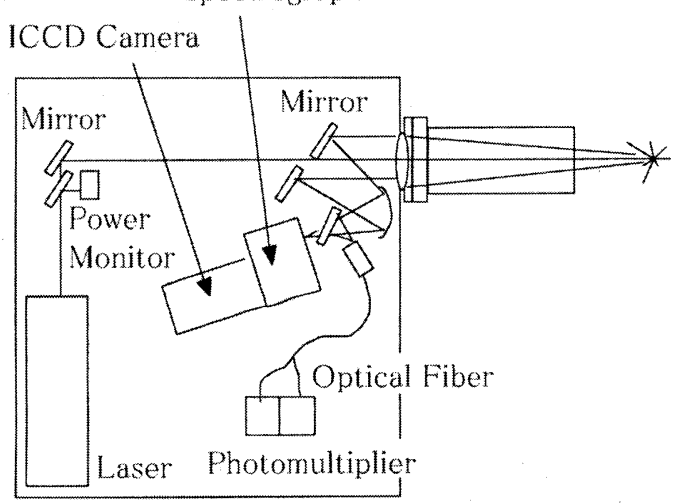

(a) Optical Setup in LIBS Unit

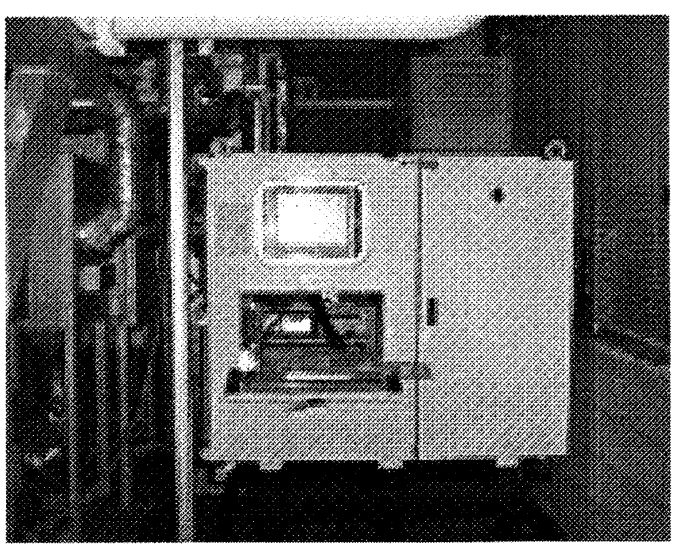

(b) Photo of LIBS Unit

Fig.4 Automated LIBS unit. 
に集光し,レーザー照射方向に1〜2mmのプラズマを生成 させる．計測対象から発生したプラズマ光を分光器に入 射し, $\mathrm{Na}, \mathrm{K}$ の発光強度をICCDカメラにて検出する. ICCD カメラからの信号をコンピュータで処理し,アルカリ成分 濃度を求める。 Na, K, NのLIBSスペクトルをFig.5に示す。 本装置では, $\mathrm{Na}, \mathrm{K}$ の濃度を, Nの信号強度を用いて補正す ることにより,長期の安定計測を可能としている.

\section{4. 試験結果及び考察}

\section{1 大気圧長期試験結果}

大気圧, 常温下における Na, K濃度校正結果をFig.6に示 す. Na, K濃度とLIBS計測結果は良い一致を示しており,本 LIBS装置がppbレベルの計測感度を有していることを確認 した.

テスト燃焼炉を用いた長期試験結果をFig.7に示す。ア ルカリ成分として $\mathrm{NaCl}, \mathrm{Na}_{2} \mathrm{SO}_{4}$ を数時間間隔で添加した。 LIBS計測では, ppbレベルのNa濃度を約 1 分間隔で計測し た。 $\mathrm{Na}$ 添加時点でLIBS計測結果は急激に立ち上がり, $\mathrm{Na}$ 添 加を停止すると, $\mathrm{Na}$ 添加しないNa濃度まで立ち下がって

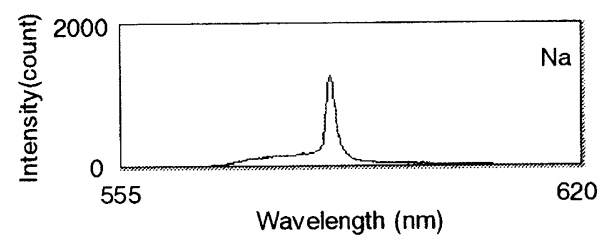

(a) $\mathrm{Na}$

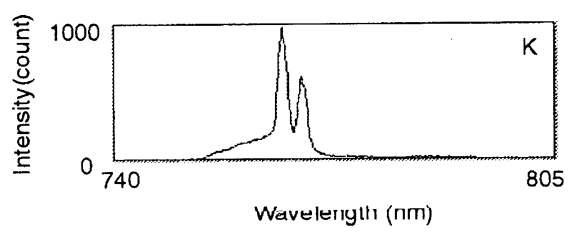

(b) $\mathrm{K}$

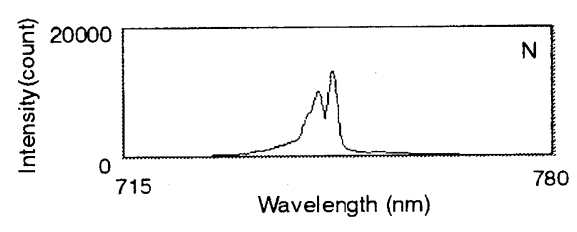

(c) $\mathrm{N}$

Fig.5 LIBS spectra.

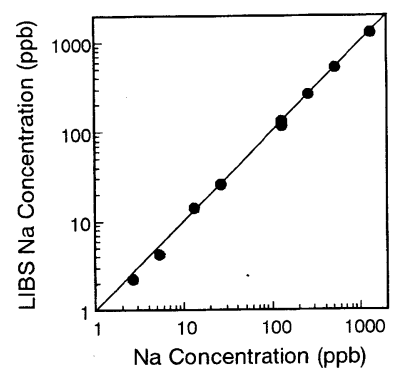

(a) $\mathrm{Na}$

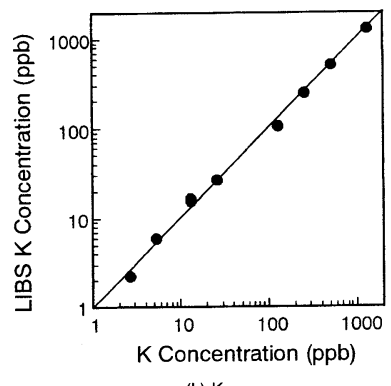

(b) $\mathrm{K}$
Fig.6 $\mathrm{Na}$ and $\mathrm{K}$ calibration result at $\mathrm{P}=0.1 \mathrm{MPa}$.

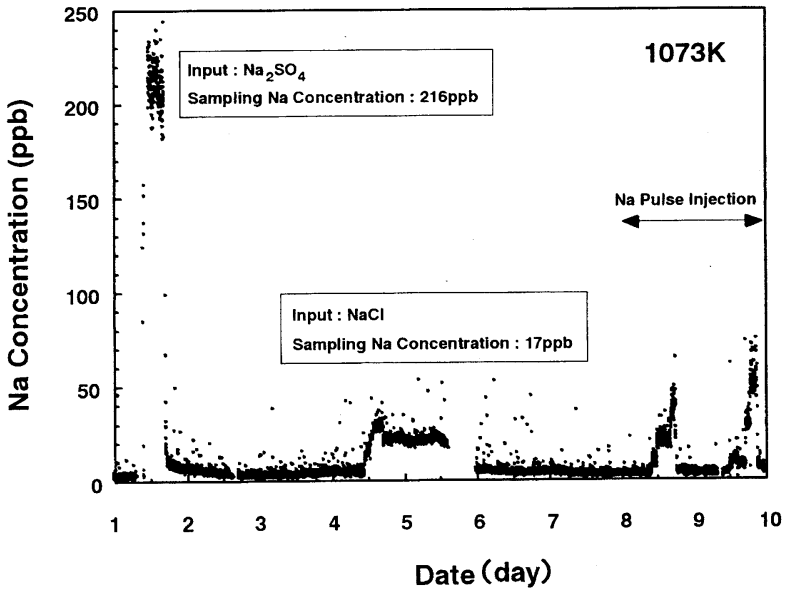

Fig.7 Long term Na monitoring result.

おり,LIBSの早い応答性能が確認できたＮNaを添加しない ときには, 燃料及び空気より流入する数 $\mathrm{ppb}$ 程度の $\mathrm{Na}$ 成分 が計測されている。

Fig.7の8日〜9日にはNa溶液をパルスインジェクション した．添加するNa濃度を上昇すると, LIBS計測值が段階的 に上昇することが確認できた。このような変化は, 従来の サンプリング法では計測できず, LIBSの特長の一つであ る.

燃焼ガスにおける従来のサンプリング計測值とLIBS計 測值との比較をFig.8に示す．LIBS計測值とサンプリング 法とは良い一致を示しており, 燃焼ガス環境下における LIBS適用性を確認できた。

\section{2 高圧, 高温試験結果}

高温・高圧場における Na, K成分のLIBS計測結果をFig.9 に示す. $3 \mathrm{MPa}$ までの高圧場においても, ppbレベルのNa, K が検出でき, 高温・高圧環境下におけるLIBS法の適用性を 確認できた。

高圧場でのLIBS計測では, レーザー照射後のLIBS信号を 検出するまでのディレイ時間が重要となる．Naにおける ディレイ時間とLIBS信号S/N比との関係をFig.10に示す. 圧力が高い程, プラズマの消滅時間が短くなることが確認 できた. LIBSでは, 計測部圧力がディレイ時間等の計測パ ラメータに大きく影響を及ぼすため, 各圧力において, 最

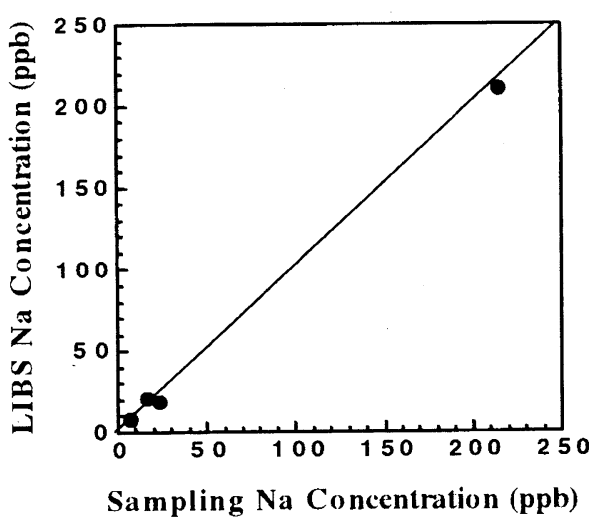

Fig.8 Comparison between LIBS and sampling results in burned gas conditions. 


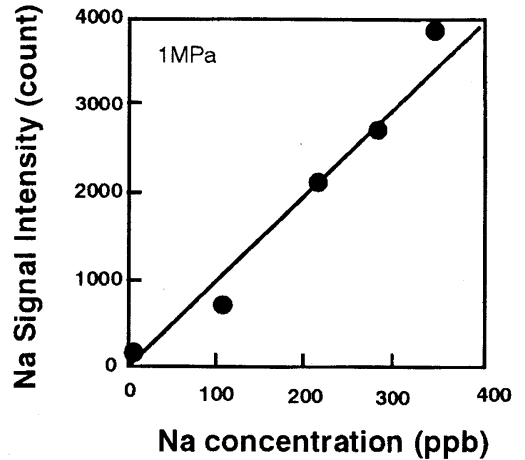

(a) $\mathrm{Na}, \mathrm{P}=1.0 \mathrm{MPa}, \mathrm{T}=870 \mathrm{~K}$

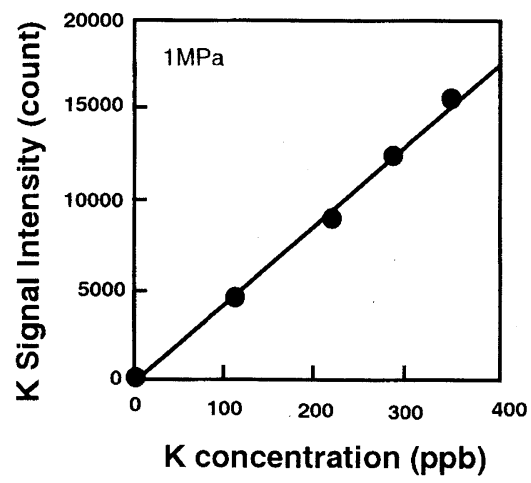

(c) $\mathrm{K}, \mathrm{P}=1.0 \mathrm{MPa}, \mathrm{T}=870 \mathrm{~K}$

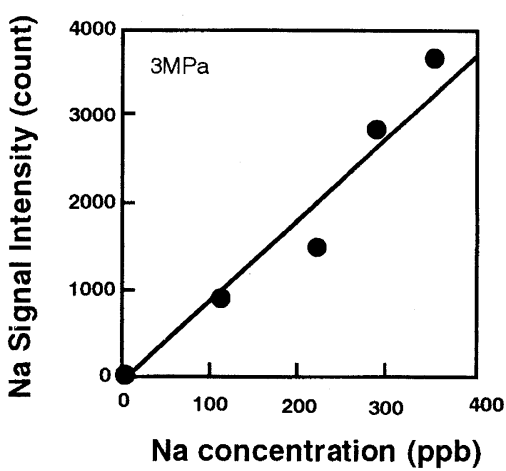

(b) $\mathrm{Na}, \mathrm{P}=3 . \mathrm{MPPa}, \mathrm{T}=870 \mathrm{~K}$

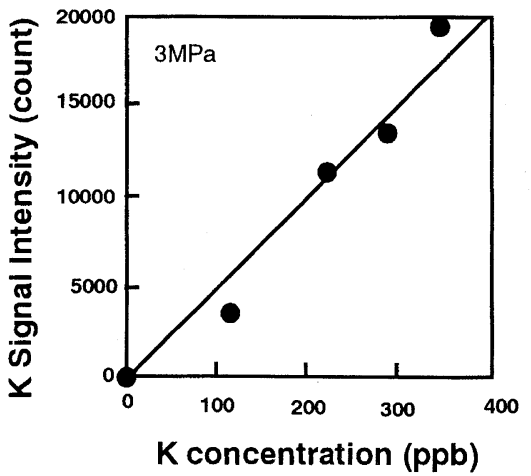

(d) $\mathrm{K}, \mathrm{P}=3.0 \mathrm{MPa}, \mathrm{T}=870 \mathrm{~K}$

Fig.9 Relationship between LIBS signal and alkali metal concentration at high pressure.

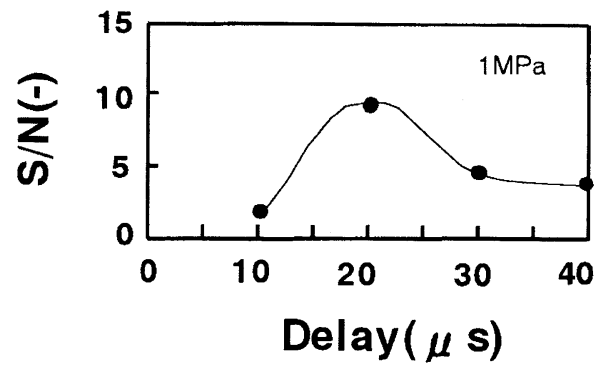

(a) $\mathrm{Na}, \mathrm{P}=1.0 \mathrm{MPa}, \mathrm{T}=870 \mathrm{~K}$

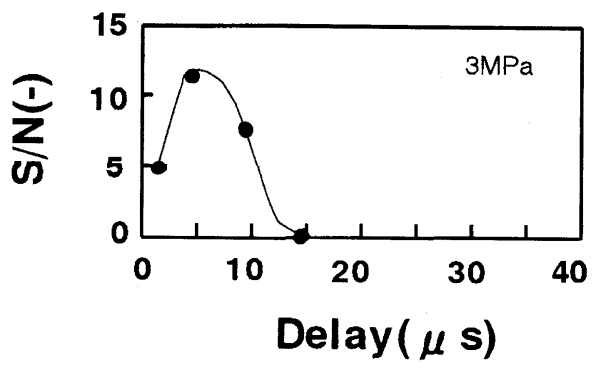

(b) $\mathrm{Na}, \mathrm{P}=3.0 \mathrm{MPa}, \mathrm{T}=870 \mathrm{~K}$

Fig.10 Relationship between delay time and $\mathrm{S} / \mathrm{N}$ ratio at high pressure.

適パラメー夕の選定が重要となる。

圧力に対する $\mathrm{Na}, \mathrm{K}, \mathrm{N}$ の設定デイレイ時間変化を Fig.11 に, 各成分の発光ラインの上位準位エネルギ值をTable 1 に 示す．圧力上昇に伴い,ディレイ時間を短くする傾向は同 ビであるが,成分毎にディレイ時間は異なる。これは,ディ レイ時間が各成分の発光ラインの上位準位エネルギ值に 大きく依存するためであり, 圧力が高いと周囲分子との相

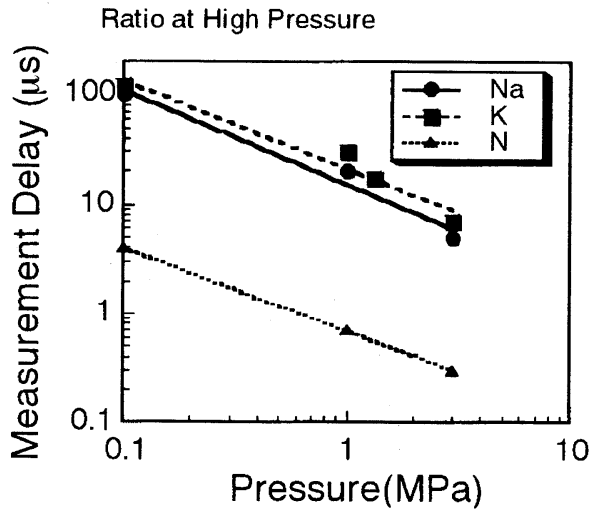

Fig.11 Pressure dependence of delay time condition on $\mathrm{Na}$, $\mathrm{K}$, and $\mathrm{N}$.

Table $1 \mathrm{Na}, \mathrm{K}$, and N LIBS signal.

\begin{tabular}{ccc}
\hline \hline Atom & $\begin{array}{c}\text { Emission } \\
\text { wavelength }(\mathrm{nm})\end{array}$ & $\begin{array}{c}\text { Upper state } \\
\text { energy }\left(\mathrm{cm}^{-1}\right)\end{array}$ \\
\hline $\mathrm{Na}$ & 589.0 & 16973 \\
$\mathrm{~K}$ & 766.5 & 13043 \\
$\mathrm{~N}$ & 746.8 & 96751 \\
\hline \hline
\end{tabular}

互作用が大きくなり,プラズマ温度が短時間に低下するた め,短いデイレイ時間設定が必要となる.

4.3 考 察

本試験では, 背景光や排ガス中の他成分による干渉はな く,精度良く各成分のLIBSスペクトルが観察された。これ は,ノイズ成分となる背景光などに比較LLIBS信号強度が 
強いこと,及びアルカリ成分が他の原子に対し強い発光強 度を有していることによるものである。また, 計測空保護 用空気パージ機構を採用しているため,一ヶ月間の長期試 験でも, 空污れによる光透過率の減少は認められなかっ た. LIBSでは, 計測成分の濃度を求める上で, 信号強度の 絶対値ではなく, 信号強度比を用いるため, 万一計測空の 污れ等が発生しても,その影響を受けにくい特長を有して いる.

本試験により,アルカリ成分が長期間自動計測可能なこ とを実証でき,かつ, 圧力の依存性が把握でき, 実プラント 等のモニタリング技術としてLIBS法が有望であることを 確認できた，長期間の計測では,レーザー装置などの各機 器の安定性も重要となる。近年, 長期間の安定作動が可能 な半導体レーザー励起固体レーザー等が加工分野を中心 に開発されてきており, 1 2年レベルで保守が不要な装置 の開発が可能と考えられる.

\section{5. 結 言}

レーザーを用いた微量成分計測法として,LIBS法を適用 し, 微量アルカリ成分の計測を行った. 本方法はppbの計測
感度を有しており,実プラントへの応用可能性を有してい ることを確認した。今後, 感度, 応答性向上などを実施し， 実用化を進めていく予定である。

謝 辞

本報告は, (財) 発電設備技術検查協会が経済産業省の委 託により実施した「高度運転監視技術開発調査」成果の一部 である，本試験の計画,実施及び評価にわたりご指導いた だいた高度運転監視技術開発調査委員会委員長堀尾 正靶東京農工大学教授, 高度運転監視技術開発調査分科会 主查吉川 典彦名古屋大学教授, 分科会副主査守富 寛岐阜 大学教授並びに委員各位に深謝致します。

\section{参考文献}

1) L. W. Peng, W. L. Flower, K. R. Hencken, H. A. Johnsen, R. F. Renzi, and N. B. French: Process Control Qual. 7 (1995) 39.

2) D. K. Ottesen, L. L. Baxter, L. J. Radziemshi, and J. F. Burrows: Energy \& Fuels 5 (1991) 304.

3）出口 祥啓, 岩嵭 誠司, 石橋 直彦：三菱重工技報 35 (1998) 222

4) K. Holtzclaw, J. Moore, and C. L. Senior: AIAA-93-0791 (1993). 